\title{
A broader picture of Rutherford's geophysicists
}

In his interesting article "Rutherford's Geophysicists" (PHYSICS TODAY, July 2010, page 42), Greg Good says, "Rutherford and others believed that the heat given off by radioactive elements derailed the arguments that Lord Kelvin had used to support a youthful Earth and to critique Charles Darwin's theory of evolution by natural selection." Given that this belief undoubtedly influenced the development of geophysics, I find it interesting that the primary error in Kelvin's estimate was not his neglect of a heat source but rather his neglect of any means other than conduction for getting heat out of Earth. Indeed, if Earth had zero radiogenic heat sources, it would very likely convect, slowly eliminating the great heat produced from gravity when the planet formed. Kelvin's tens of millions of years-roughly the typical age of the ocean floor-would still be a reasonable estimate for the conductive diffusion time of heat through the thermal boundary layer. This is not something related to Earth's total age, because the mantle has overturned many times in Earth history.

At the time Kelvin proposed his argument, the fact that much of Earth is solid had not yet been well established. Therefore, the idea that Earth's deep interior convected was not unreasonable, and later arguments about the ability of solids to flow would not have been a problem. He could have obtained a roughly correct answer for Earth's age by merely dividing the planet's total heat content by its total heat output;

Letters are encouraged and should be sent by e-mail to ptletters@aip.org (using your surname as "Subject"), or by standard mail to Letters, PHYSICS TODAY, American Center for Physics, One Physics Ellipse, College Park, MD 20740-3842. Please include your name, affiliation, mailing address, e-mail address, and daytime phone number on your attachment or letter. You can also contact us online at http://www.physicstoday.org/ $\mathrm{pt} /$ contactus.jsp. We reserve the right to edit submissions. that calculation yields around 10 billion years for current estimates of the input numbers, and it would have been a perfectly reasonable thing to do for the understanding of cosmogony at that time. Of course, Kelvin had the misfortune to get a similar answer for the Sun's age as he obtained for Earth; the method he used roughly works for Earth but fails badly for the Sun because he was understandably unaware of fusion.

Another great scientist, Harold Urey, is responsible for posing the question of how much of Earth's heat flow comes from radiogenic heat production rather than secular cooling. The current estimate for the fraction derived from radiogenic heating is around one-half; the reason for that value is still hotly debated.

\section{David Stevenson \\ (djs@gps.caltech.edu) California Institute of Technology Pasadena}

As one who knew both Edward "Teddy" Bullard and one of Patrick Blackett's doctoral students in paleomagnetism, I read with great interest "Rutherford's Geophysicists" by Greg Good. I am concerned, though, that the article suggests, even if inadvertently, that Bullard was the first to propose electrical currents in Earth's liquidmetal core as being capable of sustaining the geomagnetic field by dynamo action and that his March 1948 paper $^{1}$ contained a dynamo model.

That paper makes no mention of the first suggestion, by Joseph Larmor in 1919, that Earth's magnetic field might be maintained by something like a dynamo in its interior. ${ }^{2}$ In a footnote in his 1948 paper (page 249), Bullard acknowledged the prior and "similar" arguments by Walter Elsasser in his two 1946 papers, but strangely does not mention Elsasser's important 1947 paper on the toroidal field modes. ${ }^{3}$ Elsasser's papers discuss at length the mathematical representation of the poloidal and toroidal parts of the geomagnetic field and the dynamics and energetics of the feedback mechanisms necessary to sustain it. But Bullard's
March 1948 paper concentrates on the secular variation rather than on dynamo action and offers only the briefest summary of possible causes of motions in the core. In fact, the first of Bullard's many papers on geomagnetic dynamo models ${ }^{4}$ was not submitted for publication until November 1948. That paper concludes with his generous acknowledgment of the influence of Elsasser's work on his own ideas.

My comments are not intended to detract from Bullard's extensive and original contributions to geomagnetic dynamo theory, only to remind readers that Elsasser did foundational work at a time when the origin of Earth's magnetism still appeared to be a nearly impenetrable mystery.

\section{References}

1. E. C. Bullard, Mon. Not. R. Astron. Soc., Geophys. Suppl. 5, 248 (1948).

2. J. Larmor, Rep. Br. Assoc. Adv. Sci. 87, 159 (1919); Engineering 108, 461 (1919).

3. W. Elsasser, Phys. Rev. 69, 106 (1946); 70, 202 (1946); 72, 821 (1947).

4. E. C. Bullard, Proc. R. Soc. London A 197, 433 (1949).

\section{Michael Rochester \\ (mrochest@mun.ca) \\ Memorial University St. John's, Newfoundland, Canada}

Having read Greg Good's excellent article, I must take issue with the statement, "Like many English children, [Bullard] attended boarding school." Although the image of boarding schools, from Tom Brown's school days to Harry Potter's, is common in English literature, the reality is that only a privileged few have attended such institutions. One wonders whether Bullard's genius would have been nurtured and recognized had he not had the advantage of a private education at a time when most children left school at an early age with only the basics.

$$
\begin{array}{r}
\text { Nick Rogers } \\
\text { (n.w.rogers@open.ac.uk) } \\
\text { The Open University } \\
\text { Milton Keynes, UK }
\end{array}
$$

Greg Good's fascinating article compares the careers of two geophysicists, 
Edward Bullard and Patrick Blackett. Both went to the Cavendish Laboratory, but that is about all they have in common.

Harold Jeffreys and Maurice Ewing, two equally prominent geophysicists who were contemporaries of Bullard and Blackett and are also mentioned in Good's article, were not Cavendish people. The major problem they faced was how to reconstruct the structure and inner processes of Earth from surface data only. They may have recognized that the problem was ill-posed and that it could only be solved numerically. But their approaches were different: Bullard and Ewing used controlled explosive sources to constrain the solution, while Jeffreys used Bayesian statistics. Their views had much to do with their approaches. Jeffreys, in the fifth edition of his treatise The Earth: Its Origin, History, and Physical Constitution (Cambridge University Press, 1970), adopted my viscoelastic Earth model and thus unwittingly opened the door to plate tectonics.

Incidentally, Good claims that Jeffreys was "a fellow of Trinity College." He was not. He became a fellow of St. John's in 1914 and held successive fellowships thereafter under different titles, always at St. John's. I was his guest at St. John's College in the late 1950s.

Cinna Lomnitz (cinna@prodigy.net.mx) National Autonomous University of Mexico Mexico City

Good replies: David Stevenson's letter raises an interesting issue that has more to do with the nature of history than with Earth's internal heat. As Stevenson notes, from our current vantage point we know that ignorance of radioactivity was not the main problem with Lord Kelvin's calculation of Earth's age. And the belief of Kelvin's peers that this invalidated his calculations "undoubtedly influenced the development of geophysics," as Stevenson says. What counts in history is what people thought at the time. Although "could haves" interest me, too, we historians usually struggle sufficiently just establishing what did happen.

I hope I did not suggest that Teddy Bullard was the first to think Earth's magnetic field might be due to electrical currents deep within. In fact, wonderful letters in which Bullard, Patrick Blackett, and Walter Elsasser debate details of such currents still exist in the Bullard archive. And even before Joseph Larmor's 1919 paper on stellar interiors, Arthur Schuster had also considered those currents in several papers. Michael Rochester's comments are much appreciated, since he knew and worked with Bullard.

As Nick Rogers points out, Bullard came from a wealthy family and experienced opportunities less available to his working-class peers. Social background is always relevant to biography. I thank Cinna Lomnitz for the welcome correction of my error regarding Harold Jeffreys. I did know that Jeffreys was a fellow of St. John's College; I spent several enjoyable weeks in the school's archives reading his manuscripts.

Bullard and Blackett actually had more in common than their interest in geophysics. Both were government advisers and department directors, both involved themselves in operational research and the governance of science. Their personalities, of course, could not have been more divergent.

Gregory Good (ggood@aip.org) American Institute of Physics College Park, Maryland

\section{Roots and risks of total nuclear disarmament}

Notably absent from Sid Drell's otherwise comprehensive review of nuclear reductions (PHYSICS TODAY, July 2010, page 30 ) is one of the most efficacious and irreversible nuclear-disarmament measures-demilitarization of fissile materials. ${ }^{1}$

Demilitarizing weapons-grade uranium and plutonium is an established industrial practice: These fissile weapons materials are blended with industrialgrade low-enriched uranium oxide, resulting in the mixed oxide that fuels commercial reactors.

In fact, most fuel rods in civilian US power reactors contain at least some weapons-origin fissile material. Civilian nuclear reactors can profitably consume weapons-source materials while rendering them militarily useless.

Fissile conversion and demilitarization is a valuable disarmament method because it is cost-effective and irreversible in the long term; the fuel supply is reliable; and industry personnel have decades of experience in the process.

Demilitarization, which applies to both fission and thermonuclear weapons, would preclude reconstruction of proven weapons and reduce fears of treaty violations among both nuclear- and non-nuclear-weapons states.

Coupled with a ban on production of weapons-grade materials, demilitarization would most durably and tangibly impede nuclear rearmament and would be attractive to a wide array of nations.

\section{Reference}

1. A. DeVolpi, Ann. Rev. Nucl. Part. Sci. 36, 83 (1986); Nuclear Insights: The Cold War Legacy, 3 vols., DeVolpi, Oceanside, CA (2009).

\section{Alexander DeVolpi \\ (waterfoxg@gmail.com) Oceanside, California}

I disagree with my friend Sid Drell about the implications of a world ostensibly without nuclear weapons. In such a world, the only countries with nuclear weapons would be Iran, North Korea, and the like. A treaty renouncing nuclear weapons would be a modern-day repeat of the folly of the 1928 KelloggBriand pact, the General Treaty for the Renunciation of War.

Such symbolic gestures are not harmless. The signatories of KelloggBriand included all the aggressors of the 1930s. Democracies are slow to recognize aggressor nations because their motives are incomprehensible to us. Our enemies arm before we realize their intent, and our defensive measures follow only after long delay. We listen to our Winston Churchills very late. As a wise Roman said: "If you wish for peace, prepare for war."

Disarmed, we would face the threat of even a single nuclear weapon without the ability to deter it. In the age of the intercontinental ballistic missile, not even the oceans offer strategic depth.

An American renunciation of nuclear weapons would be followed by a rush to proliferation as a dozen or more regional powers, no longer protected by an implicit or explicit American guarantee, build their own nuclear forces. Such a world, in which a multitude of rivalries and enmities become nuclear confrontations, would certainly be more dangerous than the present one.

Jonathan Katz

(katz@wuphys.wustl.edu) Washington University in Saint Louis Saint Louis, Missouri

Drell replies: In my article I emphasized the need for "a mechanism for international control of the entire [nuclear] fuel cycle at all stages." Establishing such a mechanism will be critical to making substantial progress toward a 